\title{
Biogeografia aplicada ao diagnóstico ambiental em áreas rurais degradadas no Vale do Paraíba paulista
}

\author{
Gerson de Freitas Junior ${ }^{1}$ \\ Anelise Aparecida Marson ${ }^{2}$ \\ ${ }^{1}$ Universidade de São Paulo - USP \\ LCB - Laboratório de Climatologia e Biogeografia do Departamento de Geografia \\ Avenida Prof. Lineu Prestes, 338. Cidade Universitária. \\ CEP 05508-000 São Paulo - SP, Brasil \\ gerson.freitas@usp.br \\ ${ }^{2}$ Universidade de São Paulo - USP \\ LCB - Laboratório de Climatologia e Biogeografia do Departamento de Geografia \\ Avenida Prof. Lineu Prestes, 338. Cidade Universitária. \\ CEP 05508-000 São Paulo - SP, Brasil \\ anemarson@yahoo.com.br
}

\begin{abstract}
This paper aims to apply the Biogeography in the diagnostic study of the conditions of the physiognomy of the vegetation in the Vale do Paraíba paulista, including forestry plantations (eucalyptus). The method used is the geographical analysis and research procedures, the literature review and field work. The working range of mapping and empirical research focus on micro-basins representing all sectors of geomorphological and vegetation of the region. Preliminary results of the study indicate that the experiences of growing eucalyptus on a small scale and non-commercial system in conjunction with riparian forests and measures to contain erosion satisfactory results in the early stages of recovery of degraded areas, reducing erosion and decreased loss of land (and nutrients) and siltation of waterways. This work is presented in the form of graphs, tables and figures, some conclusions about the conditions of land use, vegetation and relief at local and regional scale.
\end{abstract}

Palavras-chave: physionomic biogeography, ecological biogeography, environmental diagnostic, eucalyptus, environmental degradation.

\section{Introdução}

"Biogeografia Fisionômica estuda os aspectos fisionômicos dos seres vivos, ou seja, sua expressão no mosaico da paisagem. Responde, entre outras, às indagações: "a vegetação é densa ou aberta? Arbórea ou rasteira? Que formações vegetais resultam deste fato? (...)” (TROPPMAIR, 1987, p.3-4).

Este artigo corresponde a uma das etapas um estudo mais amplo, portanto, possui caráter preliminar. Está baseado na Biogeografia Fisionômica, por isso trata apenas do diagnóstico inicial em relação às áreas rurais do Vale do Paraíba. A Biogeografia Fisionômica limita-se à descrição das condições gerais da vegetação, utilizando-se para isso as observações e descrições de campo e da interpretação de mapas, imagens de satélite e fotografias aéreas. Ela possui um caráter limitado na pesquisa, mas proporciona uma primeira abordagem para se elaborar um quadro das condições ambientais. Para os estudos mais amplos, é necessário utilizar a Biogeografia Ecológica, pois ela estuda a distribuição geográfica dos seres vivos de forma mais aprofundada, relacionando os padrões de distribuição às condições geoecológicas do ambiente. A Biogeografia Fisionômica aproxima-se dos trabalhos clássicos da Geografia e complementa o trabalho em Biogeografia Ecológica, que tem maior relação com as pesquisas contemporâneas em Meio Ambiente, tratando das causas de impactos ambientais, alterações na paisagem e buscando propor alternativas para a recuperação e conservação. 


\section{A Teoria da Biogeografia Ecológica}

"Biogeografia Ecológica estuda as inter-relações dos seres vivos com as condições geoecológicas do meio ambiente em determinado espaço"(TROPPMAIR, 1987, p.3-4).

A Biogeografia Ecológica é uma das sub-divisões da Biogeografia, assim como a Biogeografia Fisionômica, a Biogeografia Econômica, a Biogeografia Médica, a Biogeografia Histórica, etc. De acordo com a proposta do Professor canadense Pierre Dansereau em seu "Biogeography an Ecological Perspective" (1957), o estudo do Meio Ambiente no enfoque da Biogeografia Ecológica deve ser feito envolvendo cinco etapas principais, as quais ele denomina níveis de integração. Os dados levantados a partir dos estudos em Biogeografia Fisionômica, correspondem ao quinto nível - industrial, que trata das ações humanas sobre o ambiente. De forma bastante resumida, os cinco níveis podem ser descritos da seguinte forma:

- $1^{\circ}$ nível: histórico (trata dos estudos da história geológica da área pesquisada, buscando compreender como a atual distribuição da fauna e da flora chegou aos padrões atuais);

- $2^{\circ}$ nível: bioclimatológico (trata dos estudos referentes ao clima da área, às condições meteorológicas que influenciam na distribuição dos seres vivos);

- 3 nível: sinecológico (trata dos estudos relativos às associações bióticas, comunidades, populações, etc.);

- $4^{\circ}$ nível autecológico (trata dos estudos relativos aos seres vivos no nível da espécie. É, portanto, o de menor importância para a Geografia, com caráter complementar);

- $5^{\circ}$ nível: industrial (trata dos impactos das ações humanas no meio ambiente).

Para Troppmair (1987), que trabalha na perspectiva sistêmica, a Biogeografia estuda o mesmo objeto de outros ramos do conhecimento, como a Ecologia, a Botânica, a Zoologia, mas possui um caráter específico que a aproxima da Geografia, constituindo-se como um sub-ramo desta. Enquanto a Ecologia estuda o Meio Ambiente na perspectiva vertical, buscando compreender os fluxos de energia e matéria (cadeia alimentar) tendo por base os ecossistemas, para a Biogeografia importa, sobretudo, entender o Meio Ambiente em uma perspectiva horizontal, ou seja, compreender as causas que levaram à espacialização atual dos seres vivos os padrões de distribuição. Dessa forma, a Biogeografia utiliza-se de mapas e de outros instrumentos que permitem a representação das áreas de ocorrência das populações e comunidades bióticas, importando principalmente as unidades espaciais próprias da Geografia, como os Domínios Morfoclimáticos e Fitogeográficos, por exemplo. A definição dos Domínios Morfoclimáticos e Fitogeográficos está diretamente relacionada à Biogeografia Ecológica, pois os estudos das condições geoecológicas do ambiente em relação às comunidades de vida, são necessários para que sejam delimitadas as áreas de distribuição dos seres vivos.

\section{O Uso do Solo na região}

“(...) Lei da irreversibilidade. Alguns recursos (minerais, vegetais ou animais) não se renovam por si mesmos porque eles são o resultado de um processo (físico ou biológico) que deixou de funcionar em um hábitat específico ou paisagem (DANSEREAU, 1957, p.295).

Há mais de dois séculos, tem se desenvolvido na região um processo (que continua ocorrendo nos dias atuais) de uso abusivo dos solos (ora intensivo, ora marcado pela estagnação e abandono), sem preocupação adequada com a manutenção das florestas e de outras fisionomias de vegetação nativas (como as que compõem o cerrado), bem como com a necessária conservação dos solos e dos recursos hídricos locais. Chegou-se, na atualidade, a uma condição extrema de fragmentação e isolamento das florestas atlânticas (com extinção de algumas fisionomias), dos cerrados e das matas ciliares e também ao esgotamento e à baixa 
produtividade dos solos. Embora seja uma região com elevado índice de urbanização e industrialização, estes são fenômenos mais recentes e concentrados na história do conjunto dos municípios valeparaibanos. Por outro lado, o processo de degradação das áreas rurais tem sido comum aos municípios da região.

Gráfico 1. Evolução do desmatamento das Matas Atlânticas no Estado de São Paulo até 1962.

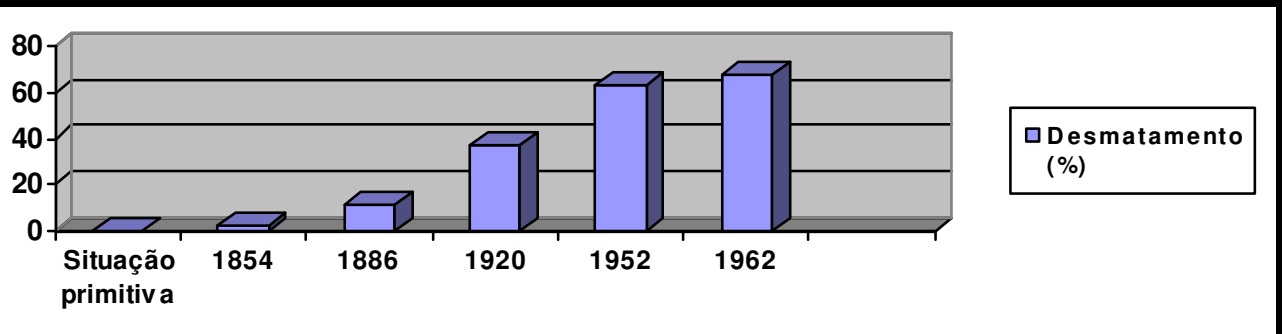

Autor: Gerson de Freitas Junior, 2007

Fonte: SÃO PAULO (1985). CONSEMA.

Predominam na região áreas rurais degradas ${ }^{1}$, inadequadas, portanto, para utilização agrícola intensiva na forma de monoculturas extensivas. Isto se deve à práticas recorrentes de uso abusivo do solo por atividades agropecuárias sem que se considerem as condições geográficas da área de forma integrada (relevo, clima, solos e substrato geológico, hidrografia e vegetação) e os impactos negativos causados à qualidade de vida das populações humanas e também à biodiversidade regional. Entre as atividades agrícolas de uso intensivo do solo na região, destaca-se a silvicultura do eucalipto, na qual as plantações têm ocupado diversos setores topográficos das áreas rurais, inclusive áreas protegidas pela legislação. Topos de morro, áreas de declividade acentuada, margens de rios, nascentes, etc.

Tabela 1. Porcentagem de matas remanescentes nos municípios do Vale do Paraíba paulista, Salesópolis e Santa Isabel.

\begin{tabular}{|c|l|}
\hline$\%$ & \multicolumn{1}{|c|}{ Municípios } \\
\hline 1 a 10 & $\begin{array}{l}\text { Caçapava, Cachoeira Paulista, Canas, Jacareí, Jambeiro, Potim, Santa } \\
\text { Branca e Taubaté; }\end{array}$ \\
\hline 10 a 20 & Aparecida, Lagoinha, Lorena, Paraibuna, Redenção da Serra e Roseira; \\
\hline 20 a 30 & $\begin{array}{l}\text { Areias, Cunha, Guaratinguetá, Igaratá, Natividade da Serra, } \\
\text { Pindamonhangaba, Santa Isabel, São Luiz do Paraitinga, São José dos } \\
\text { Campos, Silveiras e Tremembé; }\end{array}$ \\
\hline 30 a 40 & Arapeí, Cruzeiro, Lavrinhas, Queluz e Salesópolis; \\
\hline$>$ que 40 & Bananal, Monteiro Lobato, São José do Barreiro e Piquete. \\
\hline
\end{tabular}

Fonte: Atlas da cobertura atual das matas atlânticas no Estado de São Paulo por município, 1995-2000.

Org.: Gerson de Freitas Junior, 2007.

Considerando-se a área do Vale do Paraíba como totalmente inserida no Domínio Fitogeográfico das Matas Atlânticas (incluindo fisionomias de vegetação campestre associadas), verifica-se que, atualmente, a maior parte dos municípios diminuiu significativamente a área coberta pela vegetação original. As áreas serranas apresentam os maiores índices de vegetação remanescente, pois, dos quatro municípios com mais de quarenta por cento de matas remanescentes, dois estão localizados no Geossistema Bocaina e dois possuem parte de seus territórios no Geossistema Serra da Mantiqueira.

\footnotetext{
${ }^{1}$ Tão bem documentadas no filme "O Vale. $2^{\mathrm{a}}$ História” de João Moreira Salles.
} 


\section{ÁREA DE UM BAIRRO RURAL VALEPARAIBANO \\ BAIRRO DO PINHEIRINHO (MUNICÍPIO DE REDENÇÃO DA SERRA - SP)}

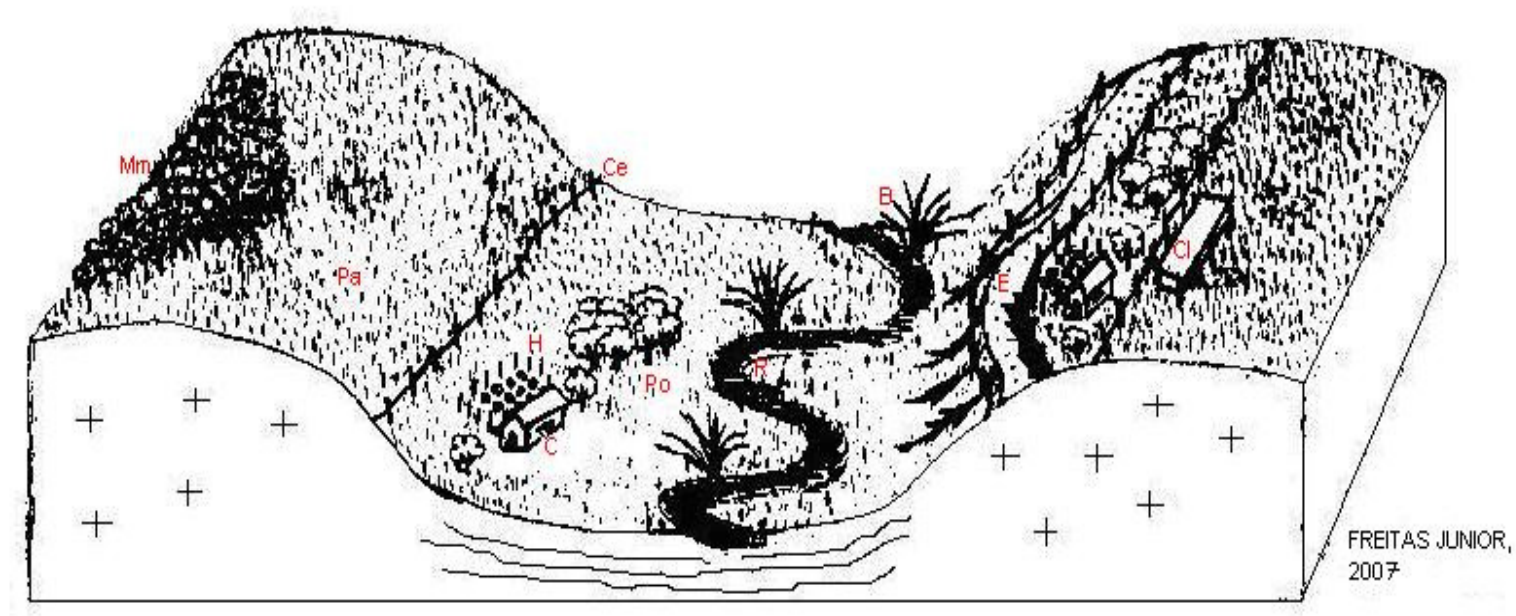

LEGENDA

\begin{tabular}{|ll}
\hline C - Casa & Po- Ponar \\
H - Horta & R - Córrego/ Riacho \\
B- Bambuzal & E - Estrada \\
Pa-Pasto & Mm-Mancha de mata \\
Cl- Curral & Ce-Cerca \\
\hline
\end{tabular}

Figura 1. Bloco diagrama das formas de utilização do solo no espaço rural do Vale do Paraíba paulista. Autor: Gerson de Freitas Junior, 2007.

Repetem-se de forma monótona, por toda a região, paisagens de morros e serras de pastos estagnados, muitos dos quais abandonados à espera da valorização imobiliária. Os pequenos bairros rurais, com pequenas e médias propriedades, apresentam um número muito restrito de formas de uso do solo. Destaca-se o turismo dos finais de semana em segundas propriedades, a pecuária leiteira tradicional de baixo rendimento (com gado disperso nos morros), pequenos cultivos de hortaliças e frutas (muitos dos quais sem preocupação com as curvas de nível) e pequenas criações de animais. Encontram-se pequenos fragmentos de matas nos topos de morros e bambuzais junto aos riachos intra-glebas muito característicos da região. Nessas áreas, é frequente a existência de grandes ravinas, resultado de processos erosivos intensificados pelo inadequado uso do solo há vários anos.

Os problemas ambientais existentes seriam decorrentes de uma perspectiva fragmentada e restrita dos modelos de uso do solo implementados nas áreas rurais do Vale do Paraíba. Essas áreas rurais necessitariam de novos Modelos Territoriais, que levassem em consideração as características geográficas, ecológicas e biológicas de forma integrada, no Vale do Paraíba e nas áreas relacionadas, priorizando a recuperação das áreas rurais, a redinamização econômica (baseada em cultivos agroflorestais diversificados) e o reflorestamento de caráter ecológicoeconômico. A continuidade do uso intensivo do solo, representado pelo aumento crescente da área cultivada com eucaliptos, e a não aplicação de medidas efetivas e abrangentes de 
recuperação e revitalização das áreas rurais da região poderia levar a uma situação ainda mais crítica e difícil de reverter do que a atual.

A maioria das municípios da região apresenta elevados índices de desmatamento das áreas originais das matas atlânticas (com consequente degradação), como mostram a Tabela $\mathbf{1}$ (página 3) e a Figura 2 (página 5), e necessitam, portanto, de medidas urgentes de repovoamento vegetal, com enfoque prioritário paras as micro-bacias hidrográficas, principalmente as localizadas nos Geossistemas Vale do Paraíba e Mar de Morros.

"Erosão do solo é uma das consequências usuais do desmatamento excessivo. O solo fino que cobre as rochas cristalinas (...) é facilmente lavado para longe e não se restaura de imediato quando [as árvores que o seguravam] são derrubadas. Áreas de topografia íngreme, como (...) as cadeias litorâneas do Brasil (...) são especialmente vulneráveis" (DANSEREAU, 1957, p.272).

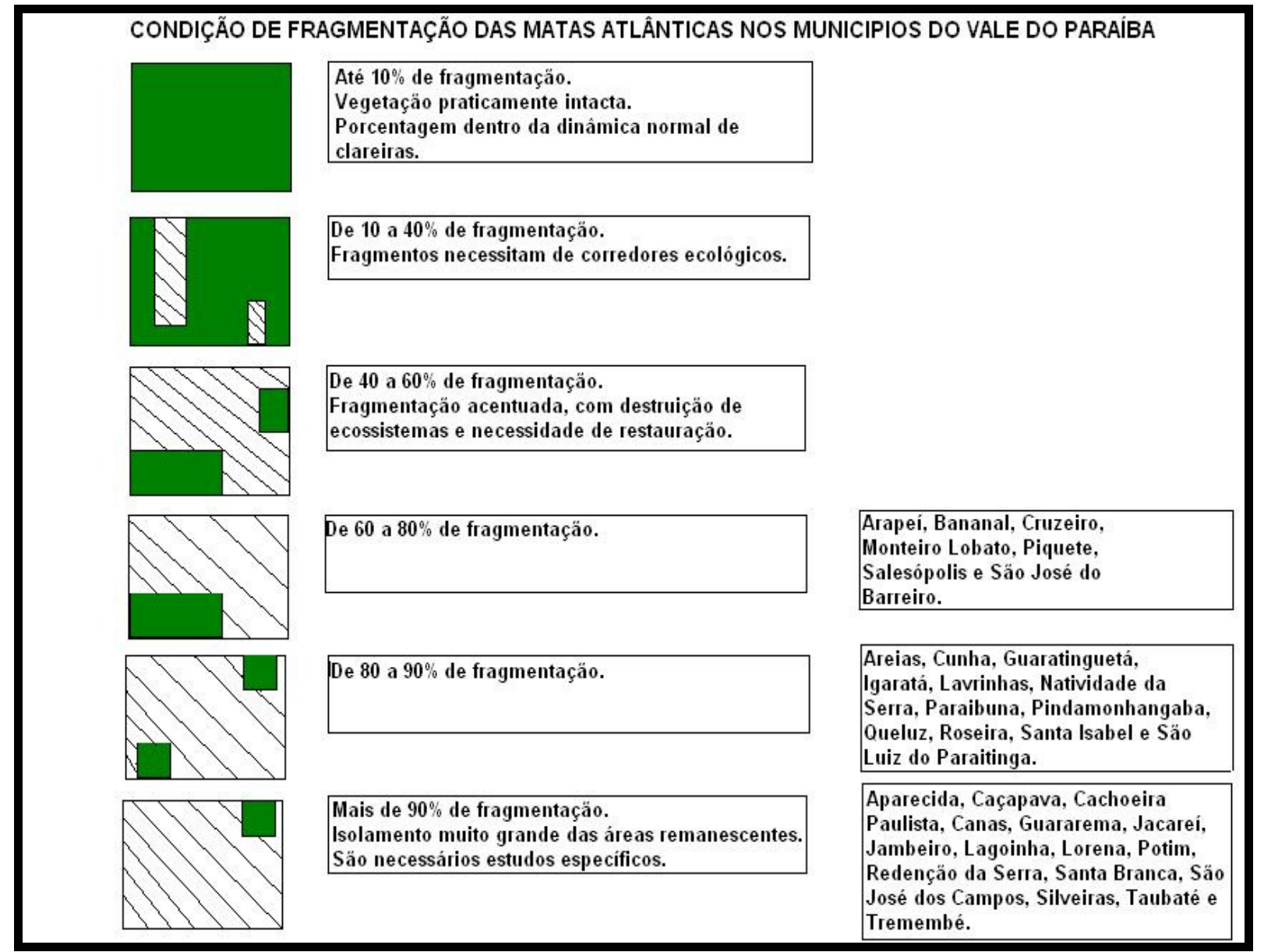

Figura 2. Condição de fragmentação das Matas Atlânticas nos municípios do Vale do Paraíba paulista. Autor: Gerson de Freitas Junior, 2007.

Conforme consta no Mapa de Potencial Agrícola do Brasil (IBGE, 1992) e em AB'SÁBER (1990), as terras do Vale do Rio Paraíba do Sul no estado de São Paulo (área core do Domínio Morfoclimático dos Mares de Morros originalmente florestados do Brasil atlântico Sudeste), são impróprias para a agricultura, devendo ser alvo prioritário de projetos e ações de recuperação de solos e de recursos hídricos, e também receber reflorestamentos ecológicos, pois apresentam os mais sérios e representativos problemas erosivos do território nacional. É necessário, portanto, que sejam elaborados trabalhos com o objetivo de compreender os fenômenos que ocorrem na região e propor alternativas à situação de degradação descrita 
acima. Buscando também, esclarecer a comunidade valeparaibana sobre a importância da proteção e recuperação das áreas rurais degradadas e de seus recursos remanescentes.

\section{Considerações finais}

Neste trabalho, utilizou-se alguns procedimentos clássicos da Geografia, como a elaboração de perfis do relevo e da vegetação, blocos diagrama e desenhos, baseados sobretudo em trabalhos de campo, com o objetivo facilitar a visualização dos fenômenos descritos em diferentes escalas de abordagem. Dessa forma, espera-se que as informações possam ser utilizadas por diferentes atores sociais no ensino e pesquisa sobre os elementos naturais e antrópicos que compõem as paisagens regionais.

Embora a situação de degradação seja bastante preocupante, medidas de recuperação têm sido implementadas para impedir ou diminuir os processos erosivos. Nesse sentido, além do replantio de espécies nativas, tem se desenvolvido experiências também com o eucalipto (RAMOS \& DIAS, 2007; RANZINI, 2002; RANZINI \& LIMA, 2002; VITAL, LIMA \& CAMARGO, 1999; e outros), apresentando bons resultados em pequena escala de cultivo (não comercial) conjugado com manutenção de matas ciliares e medidas de contenção de erosão e consequente perda de solos (e nutrientes) e assoreamento de cursos d'água.

As propriedades como a representada abaixo, frequentes na região, apresentam muitas possibilidades de estudo, como, por exemplo, na diferenciação de unidades espaciais de uso do solo, utilizando-se softwares de mapeamento. Dessa forma, serão integrados procedimentos clássicos, como os utilizados neste trabalho, com os mais modernos que se dispõe atualmente, o que gerará bases de dados importantes para o ensino nos diversos níveis escolares, bem como no Planejamento e Gestão do Território Valeparaibano.

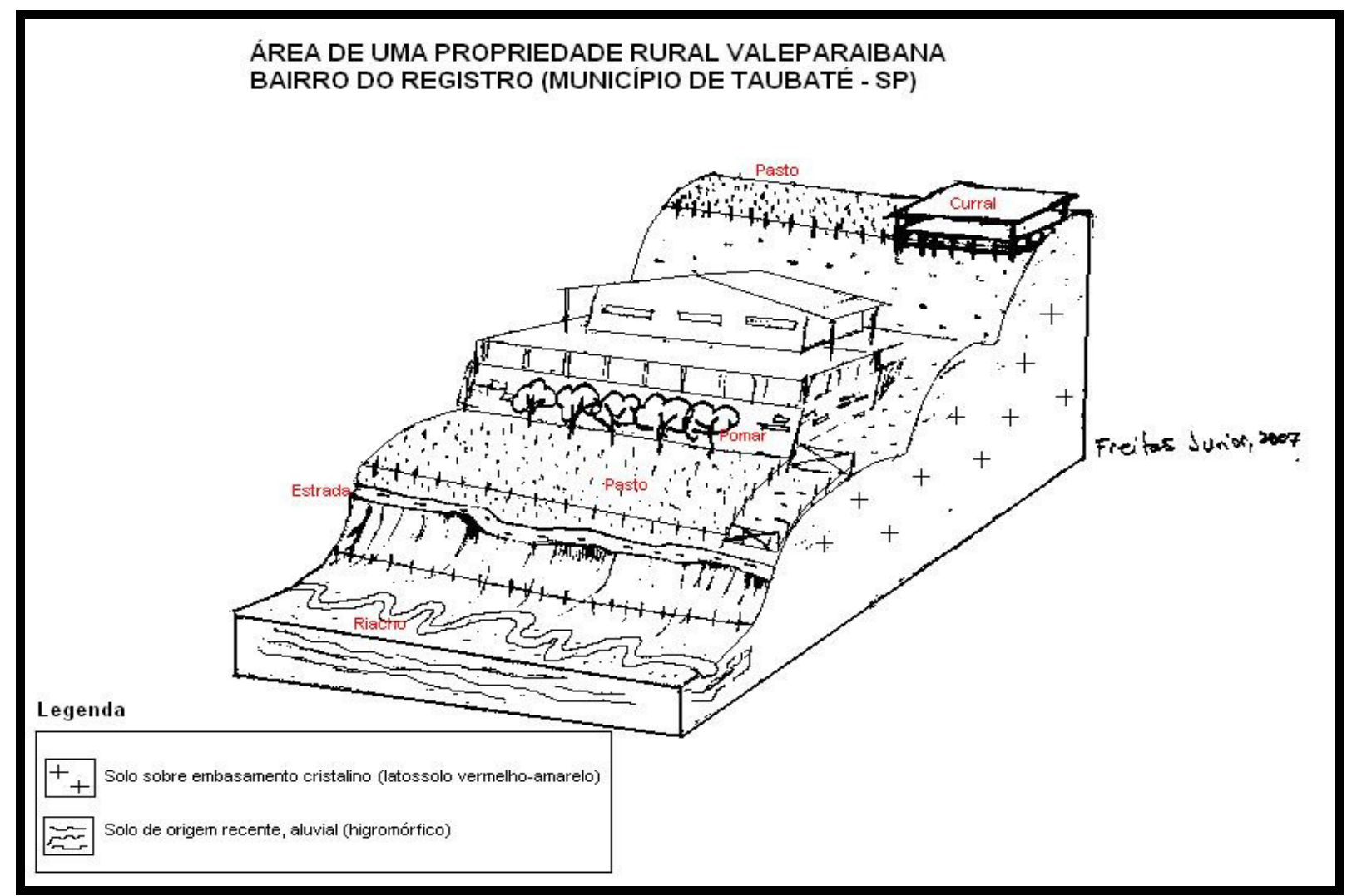

Figura 3. Bloco diagrama de área de propriedade rural típica do domínio dos morros.

Autor: Gerson de Freitas Junior, 2007. 


\section{Bibliografia}

Ab’Sáber, A. N. Os Domínios de Natureza no Brasil: potencialidades paisagísticas / Aziz Ab'Sáber - São Paulo: Ateliê Editorial, 2003;

Brasil (1992). Mapa de Potencialidade Agrícola dos Solos do Atlas Nacional do Brasil (1992). Instituto Brasileiro de Geografia e Estatística, 1992;

Folhes, M. T.; Rennó, C. D.; \& Fisch, G. Caracterização espaço-temporal do regime pluviométrico na parte paulista da bacia hidrográfica do rio Paraíba do Sul. Anais I Seminário de Recursos Hídricos da Bacia Hidrográfica do Paraíba do Sul: o Eucalipto e o Ciclo Hidrológico, Taubaté, Brasil, 07-09 novembro 2007, IPABHi, p. 359-361;

Lima, W. P. Impacto Ambiental do Eucalipto. - 2.ed.; São Paulo: Editora da Universidade de São Paulo, 1996;

Mendes, C. A. B.; \& Lima, W. P. Análise de impactos ambientais de florestas plantadas, no contexto de bacias hidrográficas: princípios norteadores. Anais I Seminário de Recursos Hídricos da Bacia Hidrográfica do Paraíba do Sul: o Eucalipto e o Ciclo Hidrológico, Taubaté, Brasil, 07-09 novembro 2007, IPABHi, p. 263270 ;

Ramos, J. G. A.; \& Dias, H. C. T. Escoamento superficial de água de chuva no cultivo do eucalipto. Anais I Seminário de Recursos Hídricos da Bacia Hidrográfica do Paraíba do Sul: o Eucalipto e o Ciclo Hidrológico, Taubaté, Brasil, 07-09 novembro 2007, IPABHi, p. 363-365 ;

Ranzini, M. Balanço Hídrico, Ciclagem Geoquímica de Nutrientes e perdas de solo em duas Microbacias reflorestadas com Eucalyptus saligna Smith, no Vale do Paraíba, SP. 1990. Dissertação (Mestrado) Escola Superior de Agricultura Luiz de Queiroz / ESALQ-USP, Piracicaba. 1990;

Ranzini, M. \& Lima, W. P. Comportamento hidrológico, balanço de nutrientes e perdas de solo em duas microbacias reflorestadas com Eucalyptus, no Vale do Paraíba, SP; Revista Scientia Forestalis - , n. 61, p. 144-159, jun. 2002;

Troppmair, H. Geossistemas e geossistemas paulistas. Rio Claro: Helmut Troppmair, 2000; 107p.;

Vital, A. R. T.; Lima, W. P. \& Camargo, F. R. A. Efeitos do corte raso de plantação de Eucalyptus sobre o balanço hídrico, a qualidade da água e as perdas de solo e de nutrientes em uma microbacia no Vale do Paraíba, SP. Revista Scientia Forestalis - Edição N 55, p. 5-16, junho de 1999. 


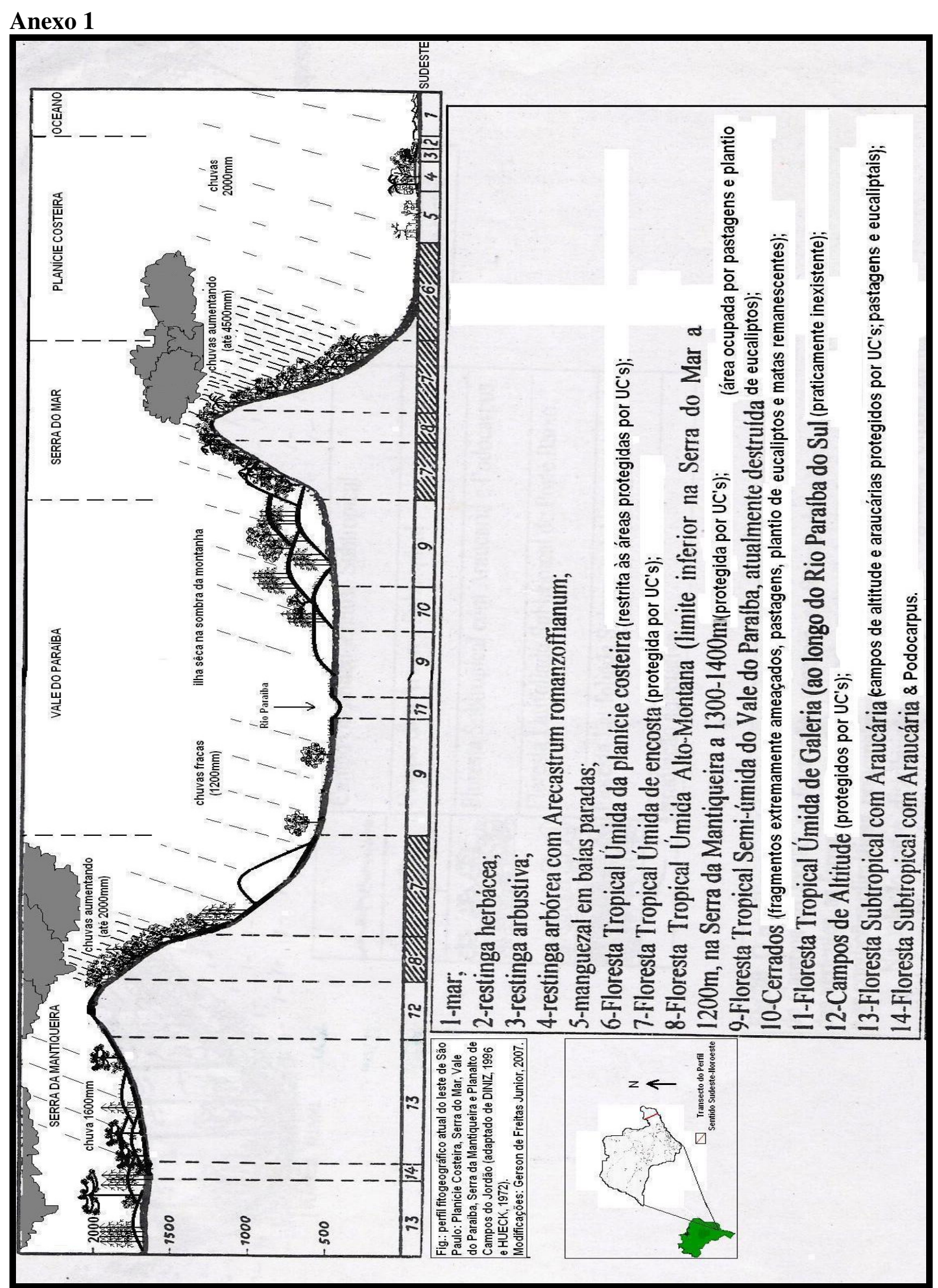

Figura 4. Perfil fitogeográfico atual do leste de São Paulo: Planície Costeira, Serra do Mar, Vale do Paraíba, Serra da Mantiqueira e Planalto de Campos do Jordão.

Autor: Gerson de Freitas Junior (2007), adaptado de Diniz, A. (1996) e Hueck, K. (1972). 